\title{
Investigating the Effect of an Online Self-Care Training Program on Perceived Stress in COVID-19 Patients
}

\section{Arash Marzban}

Aja University of Medical Sciences

\section{Zahra Farsi}

Aja University of Medical Sciences

Effat Afaghi ( $\square$ afaghi8181@gmail.com )

Aja University of Medical Sciences

\section{Mehdi Rezaei}

Aja University of Medical Sciences

\section{Mohsen Moradi}

Isfahan University of Medical Sciences

\section{Research Article}

Keywords: Self-Care, Stress, COVID-19, SARS-CoV-2, Learning

Posted Date: January 7th, 2022

DOI: https://doi.org/10.21203/rs.3.rs-1198580/v1

License: (9) This work is licensed under a Creative Commons Attribution 4.0 International License. Read Full License 


\section{Abstract}

Background: The coronavirus disease 2019 (COVID-19) caused many adverse effects, including increased stress in patients. The present study aimed to determine the effect of an online self-care training program on perceived stress in COVID-19 patients.

Methods: This quasi-experimental study was fulfilled by recruiting 132 COVID-19 patients, referred to two hospitals in Isfahan, Iran, from February 20 to August 22, 2021. These patients were selected using the convenience sampling method, and were then randomized into experimental $(n=63)$ and control $(n=63)$ groups. The online self-care training program was subsequently presented to the patients in the experimental group, during six sessions of 30 minutes for two weeks. E-learning and educational content introduced through lectures, multimedia, and instructional videos using web platforms. Then, daily followup sessions continued until one month after the intervention. The data were collected administering an individual characteristic form and the Perceived Stress Scale (PSS) at three stages before, immediately, and one month after the intervention.

Results: The mean scores of perceived stress before, immediately, and one month after the intervention in the experimental group were respectively $30.51 \pm 6.31,24.59 \pm 4.66$, and $26.57 \pm 3.82$, and they were $29.78 \pm 4.81,29.4 \pm 4.57$, and $29.11 \pm 4.73$ in that order in the control group. Moreover, no significant difference was observed between both groups at the pre-intervention stage $(p=0.467)$, while the mean scores of perceived stress in the experimental group were lower compared with those in the control group immediately $(p<0.001)$ and one month after the intervention $(p=0.001)$. The mean scores of perceived stress in the experimental group before, immediately, and one month after the intervention had also changed in a significant manner $(p<0.001)$, whereas there was no significant variation in the control group in this respect $(p=0.298)$.

Conclusions: The online self-care training program led to a reduction in perceived stress in COVID-19 patients. It is thus recommended to implement this cheap, safe, and efficient method to relieve perceived stress in such cases.

\section{Background}

Over the last two years, most countries have faced a public health emergency of international concern due to the outbreak of a new coronavirus, the severe acute respiratory syndrome coronavirus 2 (SARSCoV-2) (1), causing a pandemic of a respiratory disease called coronavirus disease 2019 (COVID-19) (2). According to the official statistics released by the World Health Organization (WHO), 252 million cases affected with COVID-19 have been thus far reported as of November 14,2021, of which over 5 million cases have lost their lives(3). With reference to the statistics of the Worldometers, 6,117,445 people have been also infected with this virus and 129,830 people have died in Iran since November 30, 2021(4).

Along with physical and physiological complications, such as headache, sore throat, gastrointestinal symptoms, diarrhea, and vomiting, evidence suggests that COVID-19 has further given rise to some major 
psychosocial issues in patients and health care providers (HCPs) (5-7). For example, it has been reported that such a condition results in higher levels of stress, anxiety, depression, irritability, sleep disorders, particularly insomnia, post-traumatic stress disorder, grief, as well as panic and fear in patients $(8,9)$. In addition, people with mental illnesses are more likely to be affected by emotional reactions due to COVID19 , which may give rise to recurrence or deterioration of their mental health conditions (10). In this line, Mohammadi et al. reported a high prevalence rate of mental health problems, particularly depression and anxiety, in Iranian COVID-19 patients (11). Most affected countries have thus underlined the need to pay much more attention to mental health in individuals, especially depression and anxiety during the COVID19 pandemic $(12,13)$. Perceived stress affects patients, their families, and HCPs. Here, perceived stress refers to the feelings or thoughts that each patient has regarding the stress as they interact with themselves and their environment, over a period of time, and how they feel about stressful life events and their ability to cope with them $(9,14)$. In this line, the results of one study in Colombia had revealed that $14.3 \%$ of adults had experienced high levels of perceived stress associated with the COVID-19 epidemic (15). Shokri et al. demonstrated that perceived stress caused by this condition had been high in Iranian population, and receiving news and information from social networks could play a significant role in intensifying perceived stress among most individuals(16). As well, Zandifar et al. found that $73.6 \%$ of COVID-19 inpatients had faced a high level of perceived stress, demanding more attention to their mental health status (14). Most studies have further shown that improving self-care skills can significantly reduce perceived stress in patients. For example, Saeidnia et al. had established that self-care training could help prevent COVID-19, manage its signs and symptoms, relieve stress, improve personal hygiene, and better communicate with HCPs (17). Self-care has been accordingly defined as the ability of individuals, families, and communities to promote and maintain health, prevent diseases, and cope with illnesses and disabilities with or without the support of HCPs (18). In other words, self-care means reviewing, planning, and performing some self-care measures that are often of importance for daily living $(19,20)$. Evidence has further shown that the COVID-19 pandemic has and will have short- and long-term consequences for mental health, and it is likely to bring devastating individual and social effects. Some researchers have also noted that the psychological effects of disasters can last for the years to come (7, 21). Therefore, appropriate interventions are essential to modify the effects of COVID-19 on physical and mental health in infected patients. Evidence has further confirmed that the use of effective training methods can play a decisive role in controlling the COVID-19 complications. For that reason, it is of utmost importance to employ fitting strategies in the training process in order to improve patient health (22). The implementation of virtual learning and face-to-face training approaches to provide educational content during the COVID-19 pandemic has been thus advocated by most researchers (23). Today, the use of e-learning by health professionals around the world has similarly redoubled (24) and its positive consequences have been reported in various studies. For example, Klimova et al. reported that e-learning could reduce perceived stress in the caregivers of patients with dementia (25). Di Giacomo et al. demonstrated that e-learning could relieve anxiety, stress and depression and improve the mental health status in students during the COVID-19 pandemic (26). Providing long-term post-crisis mental health services should be thus a priority for health care organizations in the course of the COVID-19 outbreak. Considering no eradication of COVID-19 in some countries, including Iran, as well as the value of self-care 
in preventing this condition and higher level of perceived stress in patients, this study aimed to determine the effect of an online self-care training program on perceived stress in COVID-19 patients.

\section{Methods}

\section{Participants}

This quasi-experimental study was performed in two specialized hospitals in Isfahan, Iran, from February 20 to August 22, 2021. The inclusion criteria were a definitive diagnosis of COVID-19 infection in patients using positive polymerase chain reaction (PCR) test, reading and writing ability in Persian, installation of one of the web platforms such as WhatsApp and Telegram on a smartphone, and participating in no selfcare training programs associated with COVID-19 over the past year. On the other hand, the exclusion criteria were participation in a similar training program simultaneously and unwillingness to continue contributing to the study. The sample size was estimated, according to the mean and standard deviation (SD) score of perceived stress in the study by Khadivzadeh et al. (27), with a 95\% confidence interval (Cl) and $90 \%$ test power, using the sample size formula below, by about 60 patients in each group.

$$
n=\frac{\left(\mathrm{Z}_{1-\frac{\alpha}{2}}+\mathrm{Z}_{1-\beta}\right)^{2}\left(\delta 1^{2}+\delta 2^{2}\right)}{\left(\mu_{1}-\mu_{2}\right)^{2}}=\frac{(1.96+1.28)^{2}\left((8.3)^{2}+(7.5)^{2}\right)}{(23.4-28.1)^{2}}=59.42
$$

Then, considering the $10 \%$ probability of attrition, 132 patients were included in this study using the convenience sampling method, and then randomized into experimental $(n=66)$ and control $(n=66)$ groups by the simple random allocation vis. tossing coins. During the study, three cases in the experimental group and three patients in the control group were excluded due to their unwillingness to continue participating in the study. Finally, the data related to 126 patients (that is, 63 cases in the experimental group and 63 individuals in the control group) were analyzed (Figure 1). The study participants consisted of COVID-19 patients referred to the selected hospitals in Isfahan, Iran, on an outpatient basis, who were trained and studied at home for the intervention along with a follow-up period of one month.

\section{Data Collection and Measures}

The data collection tools exploited included the individual characteristics form, the Perceived Stress Scale (PSS) (Cohen et al., 1983), and the researcher-made Self-Care Checklist.

\subsection{Individual Characteristics Form}

The individual characteristics form was comprised of items concerning age, gender, marital status, occupation, economic status, level of education, a history of underlying diseases such as diabetes and hypertension, a previous history of COVID-19, and a history of influenza vaccine injection in the past six months.

\subsection{PSS}


Perceived Stress Scale To know how stressful a person's life situations are, the 14-item PSS was developed by Cohen, Kamarck, and Mermelstein in 1983, in which each item could be answered on a fivepoint Likert-type scale (viz. none, low, medium, high, and very high), and scored 0, 1, 2, 3, and 4, respectively. The scores also ranged from 0 to 56 so that the scores 0-27 were in the group with low perceived stress and the ones equal to or higher than 28 were placed in the group with high perceived stress. Higher scores accordingly indicated higher levels of perceived stress. The PSS also measured two dimensions of (a) negatively stated items (no. 1, 2, 3, 4, 11, 12, and 14), and (b) positively stated items (no. $5,6,7,8,9,10$, and 13), scored in reverse. The validity and reliability of this questionnaire had been already confirmed in the studies by Cohen and Khadivzadeh, with the Cronbach's alpha coefficients reported to be 0.72 and 0.85 , respectively $(27,28)$. The patients' perceived stress was further collected at three stages, viz. before, immediately, and one month after the intervention.

\subsection{Self-Care Checklist}

The researcher-made Self-Care Checklist was recruited to ensure that the online self-care training program, taught to the patients in the experimental group, was fulfilled after the intervention. The checklist included four dimensions, i.e., physical, psycho-emotional, social, and spiritual. In this sense, the items in the physical dimension were doing gentle workouts three times a day, having proper nutrition, observing sleep and rest hygiene, providing a brief report of symptoms on a daily basis, and maintaining hygiene by hand-washing. The items in the psycho-emotional dimension also included exploiting coping strategies for stress, such as engaging in favorite activities, e.g., watching movies and listening to music, performing meditation techniques, and practicing mindfulness two times a day. As well, the items of the social dimension were comprised of maintaining relationships through making voice or video calls with other people and observing home quarantine instructions. Moreover, the spiritual dimension consisted of items in which each person could recorded one's spiritual strategies, such as communicating with God through prayers and worship, and any other spiritual tactics. The checklist was also in the form of a twopoint Likert-type scale including Yes and No, reviewed by the researcher item by item on a daily basis.

\section{Intervention}

Upon obtaining the written informed consent from the patients, the individual characteristics form and the PSS were completed by the patients in both experimental and control groups. The experimental group then received some explanations on how to complete the Self-Care Checklist by one of the researchers (holding Master's degree in psychiatric nursing). At the onset of the intervention, the self-care training package, which included a pamphlet and an educational booklet, was provided to the patients in the experimental group in the form of a hard copy and in person at the hospital. Then, in the early days of the disease, some self-care behaviors were taught to the patients in the experimental group in six sessions of 30 minutes for two weeks using e-learning methods as well as voice and video calls via WhatsApp. The first training session was thus held as an online lecture with slides prepared in the PowerPoint software on WhatsApp. Other training sessions were also presented in the form of PowerPoint audio along with training videos and related images on WhatsApp and Telegram. Besides, a researcher and an infectious 
disease specialist answered the patients' questions on a daily basis using the mentioned applications. The content of this package, taken from the WHO handbook, "Self-Care for Health: A Handbook for Community Health Workers and Volunteers" had further categorized self-care into several dimensions, i.e., physical dimension (namely, familiarity with the signs and symptoms of the disease, proper nutrition principles, sleep hygiene, and correct hand-washing methods), psycho-emotional dimension (viz. practicing meditation and mindfulness techniques, coping strategies for stress, and adapting to adverse conditions), social dimension (that is, communicating and maintaining long-distance social relationships during home quarantine), and spiritual dimension (explicitly, feeling connected to a larger power, for example through prayers or communication with art or nature, searching for the meaning of life, and communicating with God) (18), whose content was reviewed according to the context of Iranian population. Thus, the validity of the content of the self-care training package was confirmed by ten faculty members, as infectious disease specialists, emergency medicine specialists, as well as individuals with a Ph.D. degree in nursing education, and a master's degree in nursing. The patients in the experimental group were further asked to apply the self-care principles they had been trained at home and record daily self-care behaviors in checklists provided to them in hard copy. This checklist was completed in writing by the patients on a daily basis and was then checked by the researcher after sharing a photo on the mentioned applications. Upon reviewing the checklist based on the patients' educational needs, the researcher, after making coordination, communicated with them online at an appropriate interval and reconsidered their educational needs to improve their self-care behaviors and reduce their levels of stress.

Then, immediately and one month after the accomplishment of the intervention, the patients in the experimental and control groups were once again asked to complete the online PSS. It should be noted that the researcher was in contact with the patients in the experimental group after the intervention until one month later, and answered their questions through phone calls and social networks.

\section{Data Analysis}

The data were analyzed using descriptive tests, including mean, SD, frequency, and percentage as well as analytical ones, i.e., Chi-square test, Fisher's exact test, independent t-test, repeated measures analysis of variance (RM-ANOVA), and the post hoc least significant difference (LSD) test using the SPSS Statistics software (version 20). Kolmogorov-Smirnov test and Shapiro-Wilk test were also recruited to check the normality of the data and the significance level was considered by $p<0.05$.

\section{Results}

The mean age of the COVID-19 patients was $39.08 \pm 14.99$ (18-78) years. As well, $52.4 \%$ of the cases were female, $63.8 \%$ of the patients were married, $46.8 \%$ of the individuals had Bachelor's and Master's degrees, and $33.3 \%$ of these patients were homemakers. The independent t-test, Chi-square test, and Fisher's exact test also showed that the difference in both experimental and control groups was not statistically significant but the study group were homogeneous in terms of individual variables such as age, gender, marital status, occupation, economic status, level of education, a history of underlying diseases, a 
previous history of COVID-19, a history of influenza vaccine injection over the past six months $(p>0.05)$ [Table 1]. 
Table 1

Individual characteristics of the patients

\begin{tabular}{|c|c|c|c|c|}
\hline \multirow[t]{2}{*}{ Characteristics } & \multicolumn{2}{|l|}{ Groups } & \multirow[t]{2}{*}{$t / \chi^{2}$} & \multirow[t]{2}{*}{$\mathbf{P}$} \\
\hline & Intervention $(n=63)$ & Control(n=63) & & \\
\hline \multirow[t]{2}{*}{ Age(years) } & $36.59 \pm 15.18$ & $41.57 \pm 14.49$ & $t=-1.855$ & $0.062 *$ \\
\hline & & & $d f=124$ & \\
\hline Gender & & & $\begin{array}{l}x 2= \\
2.036\end{array}$ & $0.212^{¥}$ \\
\hline Male & $26(41.3)$ & $34(54)$ & $d f=1$ & \\
\hline Female & $37(58.7)$ & $29(46)$ & & \\
\hline Marital status & & & $\begin{array}{l}x 2= \\
0.147\end{array}$ & $0.848^{*}$ \\
\hline Married & $42(66.7)$ & $44(69.8)$ & $d f=1$ & \\
\hline Single & 21(33.3) & 19(30.2) & & \\
\hline Level of Education & & & $\begin{array}{l}x 2= \\
3.017\end{array}$ & $\begin{array}{l}0.555 \\
Y\end{array}$ \\
\hline Under diploma & $5(7.9)$ & $5(7.9)$ & $d f=4$ & \\
\hline Diploma \& Associate & $30(47.6)$ & $29(46)$ & & \\
\hline Bachelor & $20(31.7)$ & $20(31.7)$ & & \\
\hline Master & $6(9.5)$ & $3(4.8)$ & & \\
\hline Doctoral & $2(3.2)$ & $7(9.5)$ & & \\
\hline Economic situation & & & $\begin{array}{l}x 2= \\
5.937\end{array}$ & $\begin{array}{l}0.051 \\
Y\end{array}$ \\
\hline Poor (less than the cost of living) & $13(20.6)$ & $7(11.1)$ & $d f=2$ & \\
\hline Medium (at the cost of living) & $40(63.5)$ & $52(82.5)$ & & \\
\hline Good (more than the cost of living) & $10(15.9)$ & $4(6.3)$ & & \\
\hline Occupation & & & $\begin{array}{l}x 2= \\
4.306\end{array}$ & $\begin{array}{l}0.366 \\
Y\end{array}$ \\
\hline Self-employment & $10(15.9)$ & $12(19)$ & $d f=4$ & \\
\hline Official employee & $17(27)$ & $25(39.7)$ & & \\
\hline Informal employee & $4(6.3)$ & $3(4.8)$ & & \\
\hline House wife & $26(41.3)$ & $16(25.4)$ & & \\
\hline
\end{tabular}




\begin{tabular}{|c|c|c|c|c|}
\hline Characteristics & Groups & & $t / x^{2}$ & $\mathbf{P}$ \\
\hline Unemployed & $6(9.5)$ & $7(11.1)$ & & \\
\hline History of a Underlying disease & & & $\begin{array}{l}x 2= \\
0.05\end{array}$ & $1^{¥}$ \\
\hline Yes & 12(19) & 13(20.6) & $d f=1$ & \\
\hline No & $51(81)$ & $50(79.4)$ & & \\
\hline Previous history of Covid-19 disease & & & $\begin{array}{l}\chi 2= \\
2.096\end{array}$ & $0.214^{\sharp}$ \\
\hline Yes & 19(30.2) & 12(19) & $d f=1$ & \\
\hline No & $44(69.8)$ & $51(81)$ & & \\
\hline $\begin{array}{l}\text { History of influenza vaccine injection in } \\
2020-2021\end{array}$ & & & $\begin{array}{l}\chi 2= \\
0.068\end{array}$ & $1^{*}$ \\
\hline Yes & $8(12.7)$ & $9(14.3)$ & $d f=1$ & \\
\hline No & $55(87.3)$ & $54(85.7)$ & & \\
\hline
\end{tabular}

The mean score of perceived stress in the patients at the pre-intervention stage in the experimental and control groups was $30.51 \pm 6.31$ and $29.78 \pm 4.81$, respectively, and there was no significant difference $(p=0.467)$. Nevertheless, the mean score of perceived stress in the patients in the experimental and control groups immediately after the intervention was $24.59 \pm 4.66$ and $29.4 \pm 4.57$, respectively $(p<0.001)$ and such values were $26.57 \pm 3.82$ and $29.11 \pm 4.73$ one month after the intervention, in that order $(p=0.001)$, which were lower in the experimental group than the controls [Table 2]. 
Table 2

Comparison of the scores of patients' perceived stress at before, immediately after, and 1month after the intervention in both groups

\begin{tabular}{|c|c|c|c|c|c|c|}
\hline \multicolumn{2}{|l|}{ Stage } & \multicolumn{2}{|l|}{ Groups } & \multicolumn{3}{|c|}{ Independent $t$-test } \\
\hline & & $\begin{array}{l}\text { Experimental } \\
\text { (Mean } \pm S D)\end{array}$ & $\begin{array}{l}\text { Control } \\
\text { (Mean } \pm S D)\end{array}$ & $\mathrm{t}$ & df & $\mathrm{p}$-value \\
\hline \multicolumn{2}{|c|}{ Before intervention } & $30.51 \pm 6.31$ & $29.78 \pm 4.81$ & 0.73 & 124 & 0.467 \\
\hline \multicolumn{2}{|c|}{ Immediately After the intervention } & $24.59 \pm 4.66$ & $29.4 \pm 4.57$ & -5.85 & 124 & $<0.001$ \\
\hline \multicolumn{2}{|c|}{ One month after the intervention } & $26.57 \pm 3.82$ & $29.11 \pm 4.73$ & -3.32 & 124 & 0.001 \\
\hline \multirow[t]{3}{*}{ RM-ANOVA } & $\mathbf{F}$ & 44.812 & 1.224 & & & \\
\hline & df & 2 & 2 & & & \\
\hline & $\mathbf{P}$ & $<0.001$ & 0.298 & & & \\
\hline
\end{tabular}

The study results revealed that the level of perceived stress was high in $74.6 \%$ of the patients in the experimental group and in $61.9 \%$ of those in the control group before the intervention. However, most patients in the experimental group reported low levels of perceived stress immediately (69.8\%) and one month after the intervention (55.6\%). The Fisher's exact test also showed that the level of perceived stress in the patients in the experimental and control groups did not differ significantly before the intervention, while there was a significant difference immediately and one month after it [Table 3].

Table 3

The patients' perceived stress levels at three stage in both groups

\begin{tabular}{|c|c|c|c|c|c|}
\hline \multirow[t]{2}{*}{ Stage } & \multirow[t]{2}{*}{$\begin{array}{l}\text { Perceived stress } \\
\text { levels }\end{array}$} & \multicolumn{2}{|l|}{ Groups } & \multicolumn{2}{|c|}{$\begin{array}{l}\text { Fisher's exact } \\
\text { test }\end{array}$} \\
\hline & & Experimental & Control & \multirow[t]{2}{*}{$x^{2}$} & \multirow{2}{*}{$\begin{array}{l}p- \\
\text { value }\end{array}$} \\
\hline & & $F(\%)$ & $F(\%)$ & & \\
\hline \multirow[t]{2}{*}{ Before intervention } & Low(28-56) & $16(25.4)$ & $24(38.1)$ & \multirow[t]{2}{*}{2.344} & \multirow[t]{2}{*}{0.180} \\
\hline & $\operatorname{High}(0-27)$ & $47(74.6)$ & $39(61.9)$ & & \\
\hline \multirow{2}{*}{$\begin{array}{l}\text { Immediately After the } \\
\text { intervention }\end{array}$} & Low(28-56) & $44(69.8)$ & $21(33.3)$ & \multirow[t]{2}{*}{16.811} & \multirow[t]{2}{*}{$<0.001$} \\
\hline & $\operatorname{High}(0-27)$ & 19(30.2) & $42(66.7)$ & & \\
\hline \multirow{2}{*}{$\begin{array}{l}\text { One month after the } \\
\text { intervention }\end{array}$} & Low(28-56) & $35(55.6)$ & $22(34.9)$ & \multirow[t]{2}{*}{5.414} & \multirow[t]{2}{*}{0.031} \\
\hline & High(0-27) & $28(44.4)$ & $41(65.1)$ & & \\
\hline
\end{tabular}


The RM-ANOVA results also demonstrated that the mean score of perceived stress in the patients in the experimental group had significantly diminished $(p<0.001)$, while no significant difference was observed in the control group $(p=0.232)$ [Table 2]. The post hoc LSD test outcomes additionally established that the mean score of perceived stress before and immediately after the intervention, before, and one month after the intervention, and immediately and one month after the intervention, was significantly different in the experimental group, while there was no significant difference in the control group $(p<0.001)$ [Table 4].

Table 4

The difference between the mean scores of patients' perceived stress at different stages of the study

\begin{tabular}{|lll|}
\hline Levels & Experimental group & Control group \\
\cline { 2 - 3 } & p-value & p-value \\
\hline Before and Immediately after the intervention & $<0.001$ & 0.466 \\
\hline Before and one month after the intervention & $<0.001$ & 0.312 \\
\hline Immediately after and one month after the intervention & $<0.001$ & 0.501 \\
\hline
\end{tabular}

\section{Discussion}

This study aimed to determine the effect of an online self-care training program on perceived stress in COVID-19 patients. The study findings confirmed that perceived stress in most COVID-19 patients was high, consistent with the results reported by Zandifar et al. (14). In the present study, patients' perceived stress also reduced after implementing the online self-care training program. In other words, the COVID-19 patients in the experimental group experienced less perceived stress compared with those in the control group immediately and one month after the intervention. The researchers did not find a study examining the effect of an online self-care program training on perceived stress in COVID-19 patients, but several surveys had already reflected on the effect of such programs on perceived stress in patients with other diseases. For example, Khadivzadeh et al. had described that self-care training could reduce perceived stress in women with gestational diabetes treated with insulin (27). As well, the findings of the present study were in line with the results reported by Zhao(29), Hemmati (30), and Karbalaei Harfteh (31). In contrast, Masjoudi et al. had established a weak negative correlation between self-care and perceived stress in pregnant women (32). Accordingly, the transfer of self-care knowledge and skills through elearning could augment the patients' sense of self-sufficiency and self-confidence regarding their ability to cope with stressful life events, and thus give rise to more control over thoughts and feelings while facing stress.

Given the prevalence of COVID-19 and the time constraints of HCPs, especially nurses, to train infected patients, the use of e-learning methods can be thus a good solution for implementing patient health promotion programs. Therefore, it is recommended to utilize e-learning to teach self-care in order to promote health and ease perceived stress in COVID-19 patients. 


\section{Limitations}

Among the limitations of this study was the recording of self-care behaviors by the participants themselves in the daily checklists, completed at home according to their conditions. Therefore, the accuracy of the interventions was based on trust in the patients' statements.

\section{Conclusion}

The results of the present study established that an online self-care training program reduced perceived stress in COVID-19 patients. It is thus recommended to implement this cheap, safe, and efficient method to train patients to relieve perceived stress in such cases.

\section{Abbreviations}

COVID-19: Coronavirus Disease of 2019; PSS: Perceived Stress Scale; SARS-CoV-2: novel severe acute respiratory syndrome coronavirus 2; WHO: World Health Organization; HCPs: Health care providers; PCR: Polymerase chain reaction; SD: standard deviation; RM-ANOVA: Repeated measures analysis of variance; LSD: least significant difference.

\section{Declarations}

\section{Ethical Approval and consent to participate}

This study with the code IR.AJAUMS.REC.1399.235 was approved by the Research Ethics Committee of Aja University of Medical Sciences, Tehran, Iran. Before completing the questionnaires, the main purpose of the study was described to the COVID-19 patients and the informed written consent to participate in the study was obtained. The principles of the Declaration of Helsinki, including voluntary participation, patient information confidentiality, and withdrawal right at any time, along with the provisions of the Committee on Publication Ethics were observed in this study

\section{Consent for publication}

All participants have given consent for publication. Written informed consent was obtained from the participant for publication of their individual details in this manuscript. The consent form is held by the authors' institution and is available for review by the Editor-in-Chief.

\section{Availability of data and materials}

The datasets used and analyzed during the present study are available from the corresponding author on reasonable request.

\section{Competing interests}


The authors declare no conflict of interest.

\section{Funding}

This research is supported by the Supreme Research Council of the Vice Chancellor's Office for Research and Technology at Aja University of Medical Sciences, Tehran, Iran (ID: 97001442, February 17, 2021). The funding source had no involvement in design of the study, data collection, data analysis, etc.

\section{Author contributions}

A.M. was involved in the study conception, planning, data analysis, interpretation, writing the first draft of the manuscript and data collection. Z.F. and E.A. were involved in the study interpretation and critically revising the manuscript. M.R. and M.M. involved in the data collection. All authors collaborated in the study, and all read and approved the final manuscript.

\section{Acknowledgements}

This study was approved by the Supreme Research Council of the Vice Chancellor's Office for Research and Technology at Aja University of Medical Sciences, Tehran, Iran (ID: 97001442, February 17, 2021). The researchers hereby extend their gratitude to the relevant authorities and all COVID-19 patients participating in this study.

\section{References}

1. Geneva S. Statement on the meeting of the International Health Regulations (2005) Emergency Committee regarding the outbreak of novel coronavirus 2019 (n-CoV) on 23 January 2020 [Internet]. World Health Organization. 2020 [cited 2021 Nov 5]. Available from: https://www.who.int/news/item/23-01-2020-statement-on-the-meeting-of-the-international-healthregulations-(2005)-emergency-committee-regarding-the-outbreak-of-novel-coronavirus-(2019-ncov)

2. Lu H, Stratton CW, Tang YW. Outbreak of pneumonia of unknown etiology in Wuhan, China: The mystery and the miracle. J Med Virol. 2020;92(4):401-2.

3. WHO. Weekly epidemiological update on COVID-19 - 16 November 2021 [Internet]. Emergency Situational Updates. 2021 [cited 2021 Dec 1]. Available from: https://www.who.int/publications/m/item/weekly-epidemiological-update-on-covid-19-16november-2021

4. Worldometer. COVID live update: $160,416,106$ cases and $3,333,785$ deaths from the Coronavirus [Internet]. Worldometer. 2021 [cited 2021 Dec 1]. Available from: https://www.worldometers.info/coronavirus/?fbclid=IwAR35ZFiRZJ8tyBCwazX2Nk7yJjZOLDQiZSA_MsJAfdK74s8f2a_Dgx4iVk

5. WHO. Coronavirus [Internet]. World Health Organization. 2021 [cited 2021 Sep 13]. Available from: https://www.who.int/health-topics/coronavirus\#tab=tab_3 
6. Young KP, Kolcz DL, O'Sullivan DM, Ferrand J, Fried J, Robinson K. Health care workers' mental health and quality of life during COVID-19: Results from a mid-pandemic, national survey. Psychiatr Serv. 2021 Feb 1;72(2):122-8.

7. Panchal N, Kamal R, Orgera K, Cox C, Garfield R, Hamel L, et al. The Implications of COVID-19 for Mental Health and Substance Use | KFF. Kaiser Fam Found [Internet]. 2020 [cited 2021 Sep 13];1-11. Available from: https://www.kff.org/coronavirus-covid-19/issue-brief/the-implications-of-covid-19for-mental-health-and-substance-use/

8. Xiang YT, Yang Y, Li W, Zhang L, Zhang Q, Cheung T, et al. Timely mental health care for the 2019 novel coronavirus outbreak is urgently needed. The Lancet Psychiatry [Internet]. 2020;7(3):228-9. Available from: http://dx.doi.org/10.1016/S2215-0366(20)30046-8

9. Wallace CL, Wladkowski SP, Gibson A, White P. Grief During the COVID-19 Pandemic: Considerations for Palliative Care Providers. J Pain Symptom Manage [Internet]. 2020;60(1):e70-6. Available from: https://doi.org/10.1016/j.jpainsymman.2020.04.012

10. Yao H, Chen JH, Xu YF. Patients with mental health disorders in the COVID-19 epidemic. The Lancet Psychiatry [Internet]. 2020;7(4):e21. Available from: http://dx.doi.org/10.1016/S22150366(20)30090-0

11. Mohammadi SM, Ashtari S, Khosh Fetrat M. The Psychological Impact of COVID-19 Pandemic on Mental Health of Iranian Population. Int J Travel Med Glob Heal [Internet]. 2020 Dec 8 [cited 2021 Nov 4];9(1):19-24. Available from: http://www.ijtmgh.com/article_120195.html

12. Gao J, Zheng P, Jia Y, Chen H, Mao Y, Chen S, et al. Mental health problems and social media exposure during COVID-19 outbreak. Hashimoto K, editor. PLoS One [Internet]. 2020 Apr 16 [cited 2020 Jul 30];15(4):e0231924. Available from: https://dx.plos.org/10.1371/journal.pone.0231924

13. Kheradmand A, Pirsalehi A, Mahjani M, Khoshgoui B. Mental health status among hospitalized patients with COVID-19 in Iran. Iran J Psychiatry [Internet]. 2021 Jun 7 [cited 2021 Nov 4];16(3):3629. Available from: https://ijps.tums.ac.ir/index.php/ijps/article/view/2251

14. Zandifar A, Badrfam R, Yazdani S, Arzaghi SM, Rahimi F, Ghasemi S, et al. Prevalence and severity of depression, anxiety, stress and perceived stress in hospitalized patients with COVID-19. J Diabetes Metab Disord [Internet]. 2020 Oct 29 [cited 2021 Sep 13];19(2):1431-8. Available from: https://link.springer.com/article/10.1007/s40200-020-00667-1

15. Pedrozo-Pupo JC, Pedrozo-Cortés MJ, Campo-Arias A. Perceived stress associated with COVID-19 epidemic in Colombia: an online survey. Cad Saude Publica [Internet]. 2020 [cited $2020 \mathrm{Jul}$ 30];36(5):e00090520. Available from: http://www.scielo.br/scielo.php? script=sci_arttext\&nrm=iso\&lng=pt\&tlng=pt\&pid=S0102-311X2020000506003

16. Shokri A, Moradi G, Piroozi B, Darvishi S, Amirihosseini S, Veysi A, et al. Perceived stress due to COVID-19 in Iran: Emphasizing the role of social networks. Med J Islam Repub Iran. 2020;34(1):2-4.

17. Saeidnia H, Mohammadzadeh Z, Saeidnia M. Identifying Requirements of a Self-care System on Smartphones for Preventing Coronavirus Disease 2019 ( COVID-19). Iran J Med Microbiol I ISSN2345-4342 Identifying. 2020;14(3):241-51. 
18. World Health Organization RO for S-EA. Self care for health: a handbook for community health workers \& volunteers. Vol. 79, Pharmacy Times. 2013. 15 p.

19. Choubey DK, Kumar P, Tripathi S, Kumar S. Performance evaluation of classification methods with PCA and PSO for diabetes. Netw Model Anal Heal Informatics Bioinforma [Internet]. 2020 Dec 1 [cited $2020 \mathrm{Jul}$ 30];9(1):1-30. Available from: https://link.springer.com/article/10.1007/s13721-0190210-8

20. Hurley AC, Shea CA. Self-Efficacy: Strategy for Enhancing Diabetes Self-Care. Diabetes Educ. 1992;18(2):146-50.

21. Teymouri F, Farsi Z. Lived experiences of military nurses from war- a mini-review. J Mil Med [Internet]. 2019 Nov 19 [cited 2021 Nov 8];21(5):427-35. Available from: http://militarymedj.ir/article-1-2000en.html

22. Farsi Z, Sajadi SA, Afaghi E, Fournier A, Aliyari S, Ahmadi Y, et al. Explaining the experiences of nursing administrators, educators, and students about education process in the COVID-19 pandemic: a qualitative study. BMC Nurs. 2021;20(1):1-13.

23. Farsi Z, Aliyari S, Ahmadi Y, Afaghi E, Sajadi SA. Satisfaction of the quality of education and virtual education during the Covid-19 pandemic in nursing students of aja university of medical sciences in 2020. J Mil Med. 2021;23(2):174-85.

24. Vaona A, Banzi R, Kwag KH, Rigon G, Cereda D, Pecoraro V, et al. E-learning for health professionals [Internet]. Vol. 25, Quaderni ACP. Cochrane Database Syst Rev; 2018 [cited 2021 Nov 8]. p. 49. Available from: https://pubmed.ncbi.nlm.nih.gov/29355907/

25. Klimova B, Valis M, Kuca K, Masopust J. E-learning as valuable caregivers' support for people with dementia - A systematic review [Internet]. Vol. 19, BMC Health Services Research. BMC Health Serv Res; 2019 [cited 2021 Nov 8]. Available from: https://pubmed.ncbi.nlm.nih.gov/31676005/

26. Di Giacomo D, Martelli A, Guerra F, Cielo F, Ranieri J. Mediator effect of affinity for e-learning on mental health: Buffering strategy for the resilience of university students. Int J Environ Res Public Health [Internet]. 2021 Jul 1 [cited 2021 Nov 8];18(13). Available from: https://pubmed.ncbi.nlm.nih.gov/34281044/

27. Khadivzadeh T, Hoseinzadeh M, Azhari S, Esmaily H, Akhlaghi F, Sardar MA. Effects of Self-care Education on Perceived Stress in Women with Gestational Diabetes under Insulin Treatment. Evidence-based Care [Internet]. 2015 [cited 2020 Aug 10];16(5):7-18. Available from: http://ebcj.mums.ac.ir/article_4850.html

28. Cohen S, Kamarck T, Mermelstein R. A global measure of perceived stress. J Health Soc Behav [Internet]. 1983 [cited 2020 Aug 15];24(4):385-96. Available from: https://www.jstor.org/stable/2136404

29. Zhao FF, Suhonen R, Katajisto J, Leino-Kilpi H. The association of diabetes-related self-care activities with perceived stress, anxiety, and fatigue: A cross-sectional study. Patient Prefer Adherence [Internet]. 2018 [cited 2021 Sep 21];12:1677-86. Available from: /pmc/articles/PMC6129026/ 
30. Hemati Z, Abasi S, MosaviasI F, Shakerian B, Kiani D. Effect of Orem's self-care model on perceived stress in adolescents with asthma referring the asthma and allergy clinic, Isfahan, 2014. Int J Community Based Nurs Midwifery. 2016;4(3):247-55.

31. FS KH, Z KM, S K. The Effect of Self-care Training on Perceived Stress, Health Literacy, and Self-care Behaviors in Women with Gestational Diabetes. Community Heal J [Internet]. 2020 Jun 21 [cited 2021 Sep 28];14(2):30-9. Available from: http://chj.rums.ac.ir/article_112948.html

32. Masjoudi M, Aslani A, Seifı M, Khazaeian S, Fathnezhad-Kazemi A. Association between perceived stress, fear and anxiety of COVID 19 with self-care in pregnant women: a cross-sectional study. Psychol Heal Med. 2021;

\section{Figures}

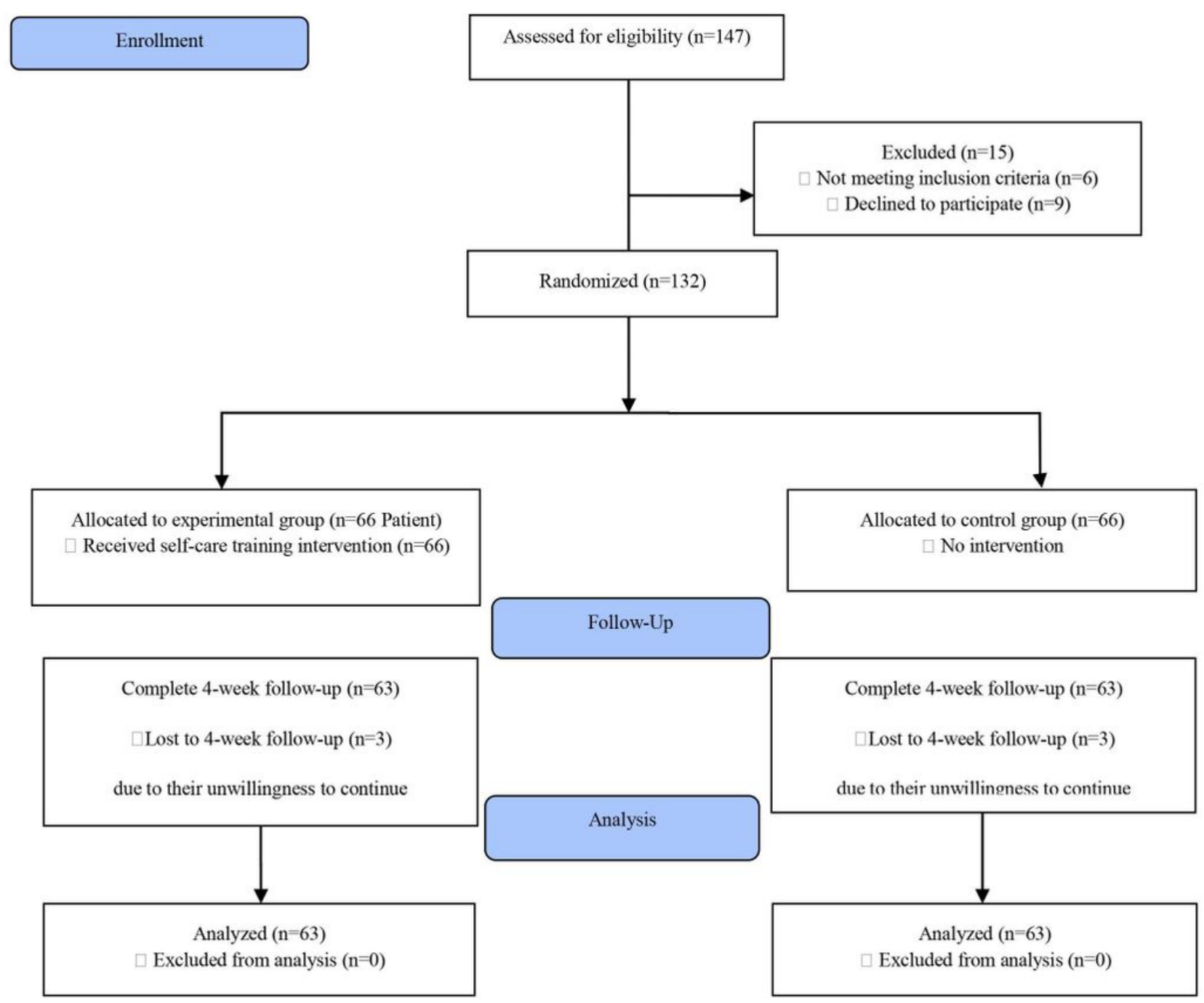


The process of study

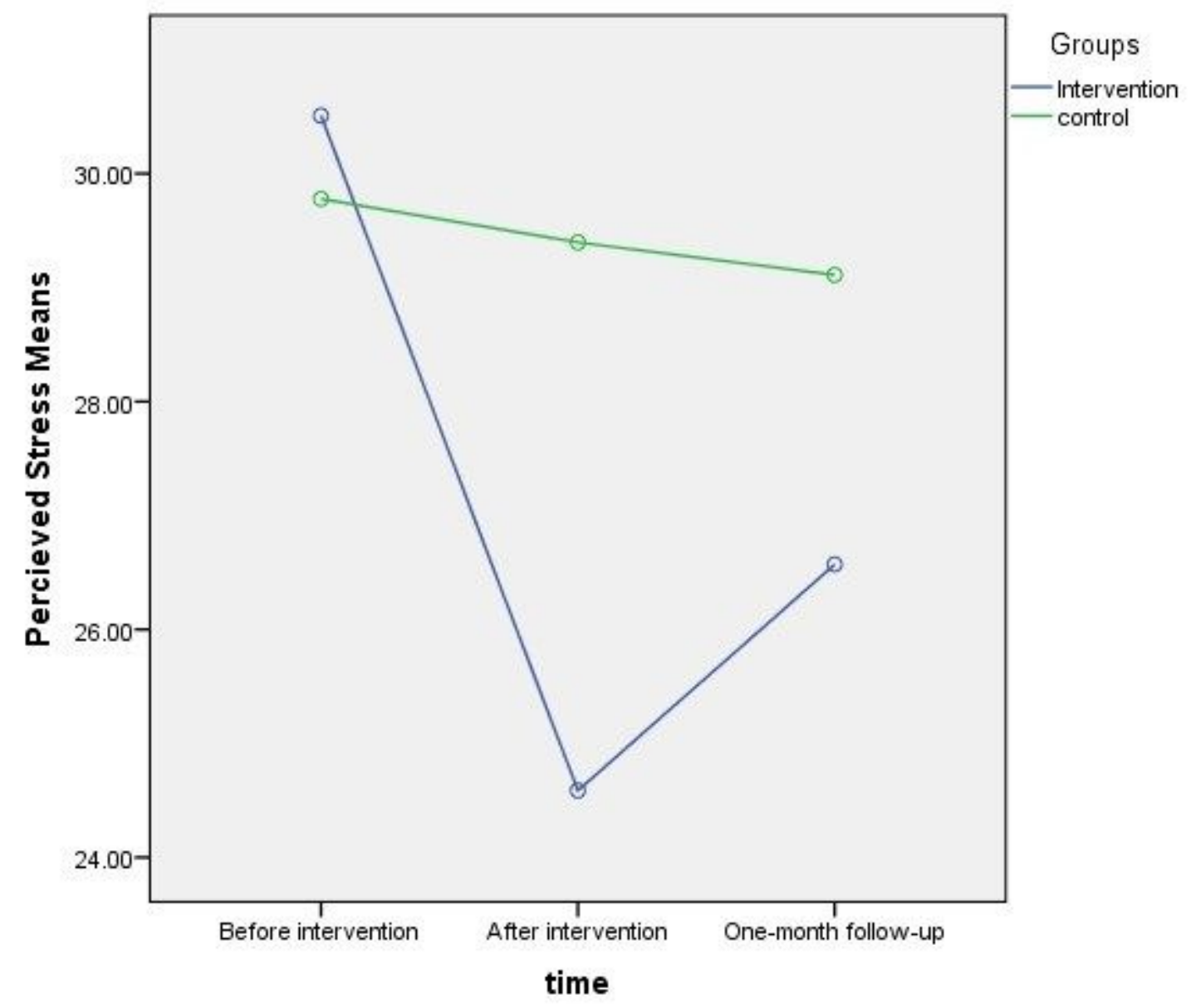

\section{Figure 2}

Comparing the trend of changes in the mean scores of perceived stress in the experimental and control groups at three stages before, immediately, and one-month after the intervention 